\title{
The Interactive Impact of Land Cover and DEM Resolution on the Accuracy of Computed Streamflow Using the SWAT Model
}

\author{
Mahmoud Al-Khafaji • Fouad H. Saeed • Nadhir \\ Al-Ansari $(D$
}

Received: 28 May 2020 / Accepted: 13 July 2020 / Published online: 28 July 2020

(C) The Author(s) 2020

\begin{abstract}
Twenty daily time step-based SWAT simulation models for the Duhok, Adhaim and Dokan dam watersheds, in Iraq, were implemented using five land cover (LC) and digital elevation model (DEM) of different resolutions. The optimal LC and DEM for computing the most accurate streamflow for each watershed were specified. Results indicated that delineation of the flat watersheds is significantly affected by the DEM resolution and there was no evident trend on the computation of watersheds' total areas, boundaries, number of subbasins and stream networks. Moreover, there is no significant trend between the increase in LC and DEM resolutions and accuracy of the computed streamflow. The most accurate streamflows for the Duhok, Adhaim and Dokan watersheds were computed using LC (DEM) of $30 \mathrm{~m}, 1000 \mathrm{~m}$ and $1000 \mathrm{~m}$.
\end{abstract}

Keywords Interactive impact $\cdot \mathrm{LC} \cdot \mathrm{DEM} \cdot \mathrm{SWAT}$

\footnotetext{
M. Al-Khafaji

Civil Engineering Department, University of Technology,

Baghdad, Iraq

e-mail: 41100@uotechnology.edu.iq

F. H. Saeed

Ministry of Water Resources, Baghdad, Iraq

e-mail: fouadhussein@uowasit.edu.iq

N. Al-Ansari $(\bowtie)$

Lulea University of Technology, Lulea, Sweden

e-mail: nadhir.alansari@1tu.se
}

\section{Introduction}

Most human activities are related to water resources, the management of which requires accurate calculations. The hydrologic models are useful tools developed to simulate the total or partial hydrologic cycle. Recently, digital image data such as land cover (LC), digital elevation model (DEM) and soil data are utilized to implement hydrologic simulation models. These data are produced with a certain degree of accuracy and temporal and spatial resolution. Currently, the SWAT (soil and water assessment tool) is the most useful and commonly used tool for implementing the watershed simulation models. Comprehensive understanding of the implications of utilizing the available satellite data of different spatial resolutions on the behaviour of hydrologic simulation models is important. In general, the accuracy and reliability of the modelling results increase with increasing precision of the input data (Booij 2005; Katrin et al. 2011; Casper et al. 2011). Wolockm and Price (1994), Romanowicza et al. (2005) and Tan et al. (2015) indicated that the DEM and LC source, resolutions and the DEMs resampling technique have a significant impact on the results from hydrologic models.

Chaubey et al. (2005) studied the Moore's Creek watershed in the USA $\left(18.90 \mathrm{~km}^{2}\right)$ using the SWAT model. Seven DEM resolution scenarios $(30,100,150$, 200, 300, 500 and $1000 \mathrm{~m}$ ) were considered. They concluded that the DEM spatial resolutions between 100 and $200 \mathrm{~m}$ cause less than $10 \%$ of error, in the computed streamflow. Chaplot (2005) examined the DEM at spatial resolutions ranging between 20 and $500 \mathrm{~m}$; the result of this investigation indicated that 
spatial resolution of the DEM has a high impact on the computed streamflow. Dixon (2009) showed that the accuracy of computed streamflow using the SWAT model is sensitive to the DEM spatial resolution when using the original DEM of 90, while the resampled DEM of $90 \mathrm{~m}$ from the original DEM of $30 \mathrm{~m}$ does not have the same computed streamflow results. The study suggested that the impact of input data resolution should be investigated; also the resampling may not be sufficient in modelling streamflow using a distributed hydrologic model. Lin et al. (2013) examined DEMs of SRTM $90 \mathrm{~m}$ and ASTER $30 \mathrm{~m}$ using the SWAT; results of this investigation showed that the SRTM $90 \mathrm{~m}$ simulated the streamflow more accurately than the ASTER $30 \mathrm{~m}$.

Meins (2013) showed that there is no trend between the accuracy of computed streamflow and the increase in the number of hydrologic response units (NHRUs). Zhang et al. (2014) considered the Xiangxi River as the study area to assess the impact of DEM spatial resolution on the accuracy of the SWAT model results at 17 DEM spatial resolutions ranging from 30 to $1000 \mathrm{~m}$, concluding that the DEM resolution essentially does not affect the streamflow. Reddy and Reddy (2015) found out that NHRUs, subbasin areas, reach slopes and reach lengths varied substantially because of DEM resolutions. Furthermore, with decreasing DEM resolution, the minimum altitude increases and the maximum altitude decreases. Tan et al. (2015) found that the NHRUs, subbasins and total watershed area changed unequally with the change in the spatial resolution of the DEM. In addition, Chen et al. (2005) used two types of LC with different spatial resolutions from different sources (i.e., AVHRR $1000 \mathrm{~m}$ and LANDSAT TM $30 \mathrm{~m}$ ) to evaluate the accuracy of the streamflow computed using the SWAT; the main conclusion was that the computed streamflow was not affected by the LC data source. Moreover, Romanowicza et al. (2005) assessed the sensitivity of computed streamflow to the change in LC using the SWAT. The results showed that the computed streamflow was extremely sensitive to the quality of LC data.

The previous studies did not provide a definitive answer regarding the spatial resolution of input data that provides the most accurate watershed modelling simulation results using the SWAT, possibly because the studied watersheds displayed different characteristics. In addition, no attention has been given to the interactive impact of LC and DEM on computed streamflow.
Finally, analysis of the relationship between watershed characteristics (size and topography) and spatial input data (source and resolution) data is important to deeply understand watershed modelling.

SWAT is an efficient tool used worldwide to quantify different hydrologic components such as surface runoff, sediment and pollution as well as impact of climate change on watershed hydrology.

Two questions arise from this. Does high (fine) resolution of spatial input data give more accurate hydrologic modelling results than low (coarse) resolution? Furthermore, can we generalize the best spatial input data for the most accurate modelling in a given watershed to different watershed(s) of different topography and size?

\section{Materials and Methods}

\subsection{Streamflow SWAT Simulation Model}

The SWAT is a semi-distributed physically based hydrologic model developed to assess the reflection of land management on runoff, sedimentation and chemical variance characteristics of watersheds (Arnold et al. (1998). Depending on the topographical characteristics of the watershed, which is represented by DEM, SWAT discretizes the considered watershed into subbasins. In addition, the hydrologic parameters of the watershed such as slopes, area of subbasins, length and location of streams were extracted from the DEM. Furthermore, the SWAT obtained the depth, width, length and slope of the streams from DEM data (Rao and Yang 2010). Moreover, it subdivides the subbasins into hydrologic response units (HRUs) consisting of homogeneous LC, slope and soil type (Arnold et al. 2012). The produced distribution and NHRUs are related to the spatial resolution of input data. When slope, LC and soil type match in different grids in a watershed, the SWAT processes these grids as one HRU to compute the hydrologic parameters, evapotranspiration (ET), surface runoff (SR), groundwater (GW) and sediment yield (SY) taking place at the HRU level. Furthermore, the SWAT simulates the water balance at HRU level before runoff is routed to the streams of the subbasin and then to the contiguous subbasin (Neitsch et al. 2011). Accordingly, the SWAT is internationally considered one of the most powerful interdisciplinary tools for implementing watershed simulation and management models (Gassman 
et al. 2007). Refer to the SWAT documentation for more details (Neitsch et al. 2011).

Using the SWAT, surface runoff and streamflow routing with a daily time base can be computed using the Soil Conservation Service Curve Number (SCS-CN) and the variable storage or Muskingum method, respectively, which are optionally provided by the SWAT (Soil Conservation Service 1986). In addition, Penman-Monteith (Monteith 1965), Priestly and Tylor (1972) or Hargreaves and Samani (1985) can be used to compute the ET. Furthermore, the lateral subsurface flow and percolation through soil is computed using the storage model (Sloan 1984) and storage routing method, respectively.

\subsection{Uncertainty and Sensitivity Analysis}

The SWAT Calibration and Uncertainty Program (SWAT-CUP) is a software package developed specifically for SWAT model calibration, validation and sensitivity analysis (Abbaspour et al. 2015).

SWAT-CUP includes SUFI-2 which is an algorithm program developed for uncertainty analysis; the program processes a set of parameter ranges in multiple simulations to fit the simulated parameters in 95\% (95PPU) in most of the observations. In SWATCUP, the goodness of fit between observed and simulated could be evaluated using $\mathrm{P}$ factor (percentage of observation located inside range of simulation) and $\mathrm{R}$ factor (thickness of simulation range). SUFI-2 allows for the selection of one of multiple options of objective function such as coefficient of determination $\left(R^{2}\right)$ or Nash-Sutcliff efficiency (NS) (Nash and
Sutcliffe 1970) to optimize the simulation against the observation. If the values of $R^{2}$ and NS are greater than 0.75 , the simulation result is good whereas the result is satisfactory if the values range between 0.5 and 0.75 (Moriasi et al. 2007). The global sensitivity analysis was used to determine the most sensitive. Then, the $t$ test and $p$ value were applied to identify the sensitivity of simulation for each parameter (Abbaspour et al. 2015).

\subsection{Study Area}

The Duhok dam watershed (DUDW), Adhaim dam watershed (ADDW) and Dokan dam watershed (DODW) in Iraq were the study areas (see Fig. 1). Selection of these areas was based on the variation in topography, size, LC and data availability. Whereas the DUDW has topography of steep to gentle slopes with a small area, the ADDW and DODW have a flat topography and steep slopes with large areas.

\subsubsection{Duhok Dam Watershed}

Duhok dam was constructed on the Duhok River. The watershed of this dam is located in a mountainous zone within the Kurdistan Region at the far north of Iraq. The total area of this basin is approximately $134.4 \mathrm{~km}^{2}$, extending between the latitudes $37^{\circ} 0^{\prime} 25^{\prime \prime}$ to $36^{\circ} 51^{\prime}$ $53^{\prime \prime} \mathrm{N}$ and longitudes $42^{\circ} 50^{\prime} 46^{\prime \prime}$ to $43^{\circ} 5^{\prime} 32^{\prime \prime} \mathrm{E}$. The Linava and Garmava streams are the largest streams in the watershed; most of the Duhok Basin has deep streams and eroded land. The rocky slopes are very steep. The rain-irrigated lands such as vineyards extend

Fig. 1 Location of the study area

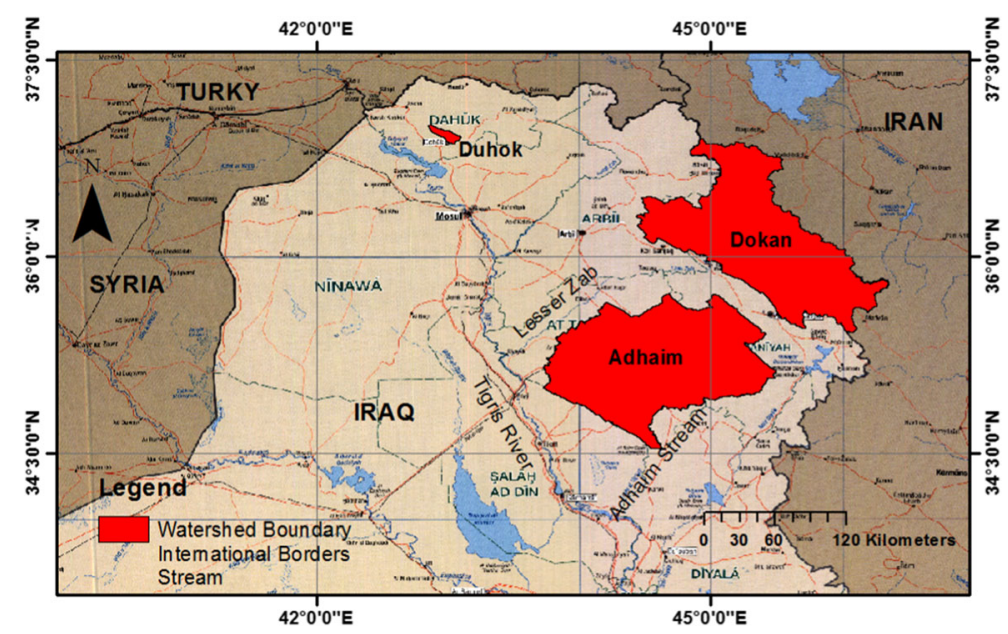


over the flat areas of this watershed. In addition, the rangeland occupies the largest part of the DUDW with a few woodlands and forestlands cover consisting of shrubs, deciduous trees, forestlands and oak trees in the steep slope zones of the watershed. However, small areas of cultivated land extend along the rivers and streams (Mohammed 2010).

\subsubsection{Adhaim Dam Watershed}

The area of this watershed covers approximately $11,600 \mathrm{~km}^{2}$; it is located within the northeast zone of Iraq between latitudes $35^{\circ} 42^{\prime} 24^{\prime \prime}$ to $34^{\circ} 33^{\prime} 8^{\prime \prime} \mathrm{N}$ and longitudes $43^{\circ} 41^{\prime} 9^{\prime \prime}$ to $45^{\circ} 27^{\prime} 31^{\prime \prime}$ E. Stream networks originate from the highlands zone of elevations from 1400 to $1800 \mathrm{~m}$ a.s.l. These networks join together at the flat zone of the watershed at an elevation of around $150 \mathrm{~m}$ a.s.l. to form the Adhaim River. Whereas barren land predominates in most of the ADDW area, a few irrigated orchard farms and cultivated lands dominate in the north-western part of the watershed. The urban area distributed above the watershed consists of cities, airports and factories which are located in Kirkuk, TuzKhormato and other small cities (Al_Amawy and Wahib 2015).

\subsubsection{Dokan Dam Watershed}

DODW is located in northeast Iraq within the Kurdistan Region in the northwest of Iran. It has a total area of $11,700 \mathrm{~km}^{2}$, extending between latitudes $36^{\circ} 51^{\prime} 16^{\prime \prime}$ to $35^{\circ} 28^{\prime} 26^{\prime \prime} \mathrm{N}$ and longitudes $44^{\circ} 26^{\prime} 25^{\prime \prime}$ to $46^{\circ} 18^{\prime} 16^{\prime \prime}$ E. It is adjoined by the Great Zab River basin from the north and the Diyala and Adhaim river basins from the south. Dokan dam is located on the Lesser Zab River. This river originates from the Iranian part of the Zagros Mountains. Shrubs and herbs predominantly cover the mountaintops while open oak forest dominates the hilly areas of the watershed. The reach of the Lesser Zab River is covered by wet forestlands, whereas the foothills, especially the plain of Arbil, have closed agricultural lands with patches of some forest and Phlomis herbs (Frenken 2009).

\subsection{Watershed Characteristic Data}

To carry out this research, the DEM, LC, soil, weather and streamflow data were collected, processed and applied as an input into the SWAT.

\subsubsection{DEM Data}

Currently, DEMs have become available with different spatial resolutions. In this research, five DEMs of different spatial resolution were used: GTOPO30 $1000 \mathrm{~m}$ (GTOPO30 2015); SRTM 250 m; SRTM 90 m (SRTM 2015) Resampled to $50 \mathrm{~m}$, it was produced from ASTER $30 \mathrm{~m}$ by applying the majority resampling technique (Tan et al. 2015) and ASTER $30 \mathrm{~m}$ (Jarihani et al. 2015).

Figures 2, 3 and 4. show the DEMs of the DUDW, ADDW and DODW, respectively. The DUDW is a small watershed. Therefore, only the DEMs of 250 , 90, 50 and 30-m spatial resolutions were applied to implement the SWAT models of this watershed.

\subsubsection{LC Data}

Digital LC images of different spatial resolutions have become widely produced and provided by several research centres and organizations. Most of the available LC images can be used for implementing hydrological simulation models with different levels of certainty in results. In this paper, five types of LC images of different spatial resolution were used: MODIS $1000 \mathrm{~m}$ and MODIS $500 \mathrm{~m}$ (Muchoney et al. 1999), ESA $300 \mathrm{~m}$ (Li et al. 2016), NGCC $30 \mathrm{~m}$ (Chen 2014) and Landsat $15 \mathrm{~m}$ (Mohammed 2010).

Figures 3 and 4 show the LC images of DUDW, ADDW and DODW, respectively. The LC image of 15-m spatial resolution was used only in the DUDW SWAT model. However, all other LC images were used in implementation of the SWAT models of the three watersheds considered.

\subsubsection{Soil Data}

The Food and Agriculture Organization of the United Nations ( 2003) provides a spatial distribution database of two soil layers (100 to $30 \mathrm{~cm}$ and 30 to 0 -cm depth) for 5000 soil types. This distribution is presented in vector form with a scale of $1: 500,000$. This database is available on the website: https://www.worldcat.org/title/digital-soilm a p - o f - t h e - w o r ld - a n d - d e r i v e d - s o i l properties/oclc/52200846. Figure 4. shows the soil maps used in SWAT models for the DUDW, ADDW and DODW. 


\section{A}

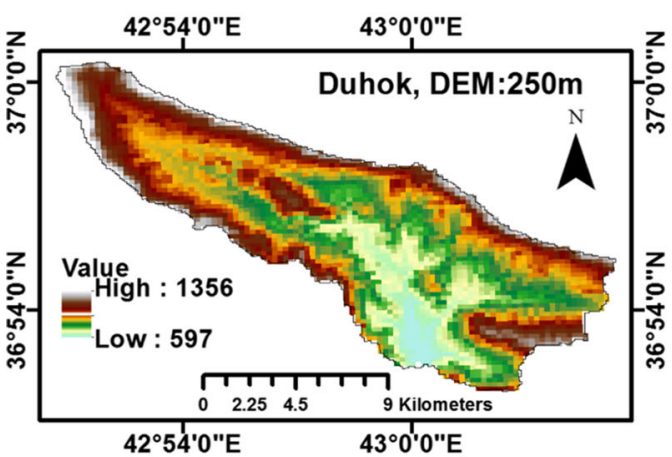

(a) $250 \mathrm{~m}$

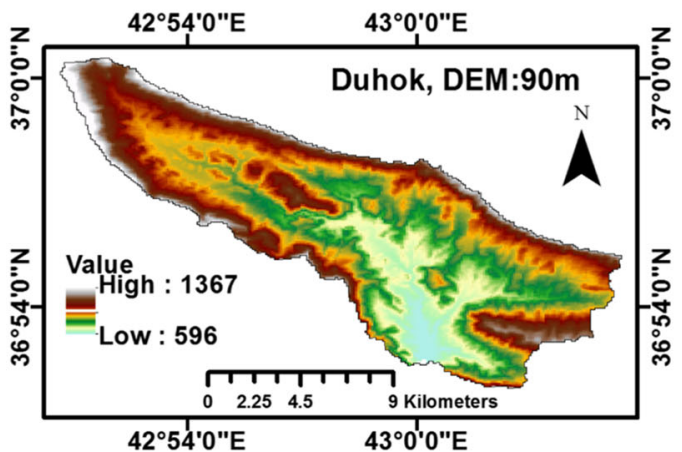

(b) $90 \mathrm{~m}$

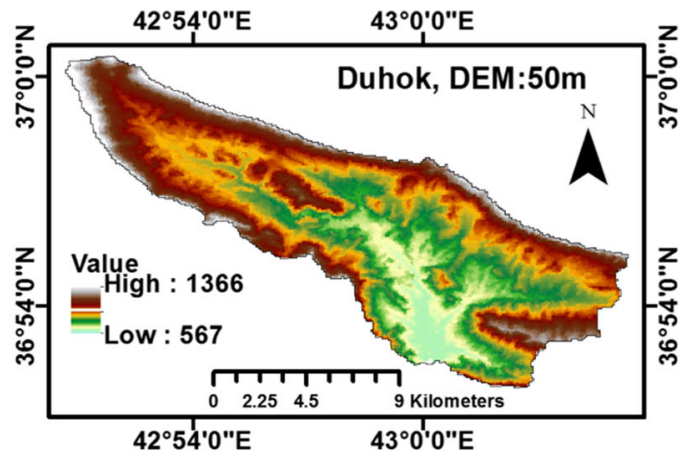

(c) $50 \mathrm{~m}$

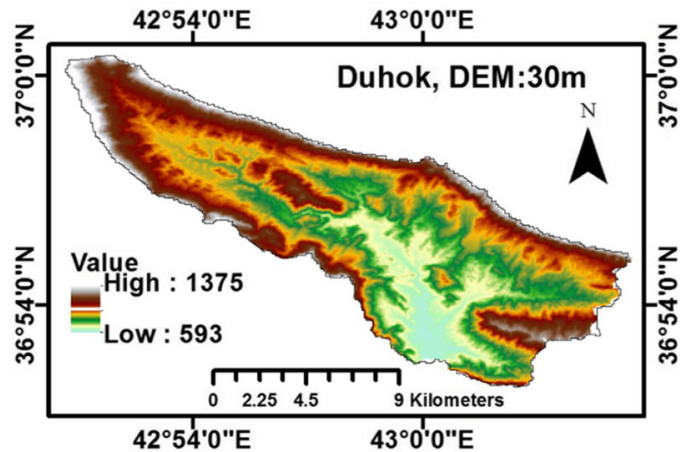

(d) $30 \mathrm{~m}$

Fig. 2 a DEMs of the DUDW: (a) $250 \mathrm{~m}$, (b) $90 \mathrm{~m}$, (c) $50 \mathrm{~m}$ and (d) $30 \mathrm{~m}$. b DEMs of the ADDW: (a) $1000 \mathrm{~m}$, (b) $250 \mathrm{~m}$, (c) $90 \mathrm{~m}$, (d) $50 \mathrm{~m}$ and (e) $30 \mathrm{~m}$

\subsubsection{Weather Data}

The Climate Forecast System Reanalysis (CFSR) dataset was used in this research (2015). All the necessary weather data for implementing the SWAT models for the considered watersheds, such as precipitation, maximum and minimum temperatures, relative humidity, wind speed and solar variations, are available in the CFSR dataset. Fuka et al. (2013) and Tomy and Sumam (2016) both indicated that the CFSR dataset gives a reasonable simulated runoff using the SWAT model. In the SWAT, there are two optional methods for the input of weather data: the simulated and the gauged weather. In this research, the gauged method was used.

\subsubsection{Recorded Streamflow Data}

The recorded streamflows at Duhok, Adhaim and Dokan Dams gauge stations were used in calibration and validation of the initial results of SWAT. According to data availability, the initial results of simulation of DUDW were calibrated and validated for the period from 2009 to 2013. While, those of ADDW and DODW were calibrated and validated for the period from 2010 to 2013. The observed streamflows for the considered watersheds were provided by the Iraqi Ministry of Water Resources (unpublished data).

\subsection{Setup of the SWAT Models}

ArcSWAT 2012 and the ESRI ArcView 10.2.2 in GIS software were used to simulate the streamflow in the considered watersheds. All LCs, DEMs and soil digital image data were projected to the WGS1984-UTM Zone $38 \mathrm{~N}$ projection. The subbasin threshold area for the DUDW, ADDW and DODW was set to 10, 200 and $200 \mathrm{~km}^{2}$, respectively. For the three watersheds, the slopes were classified into 0 to 10,10 to 20,20 to 30 , 30 to 40 and $>40$ paying careful attention to cover all 
B

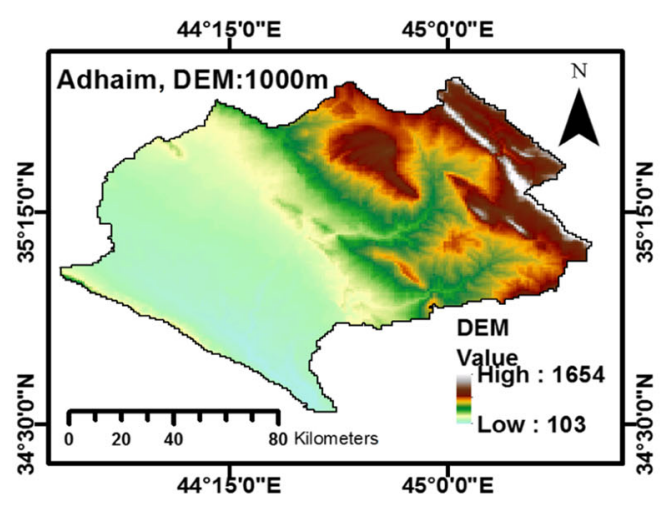

(a) $1000 \mathrm{~m}$

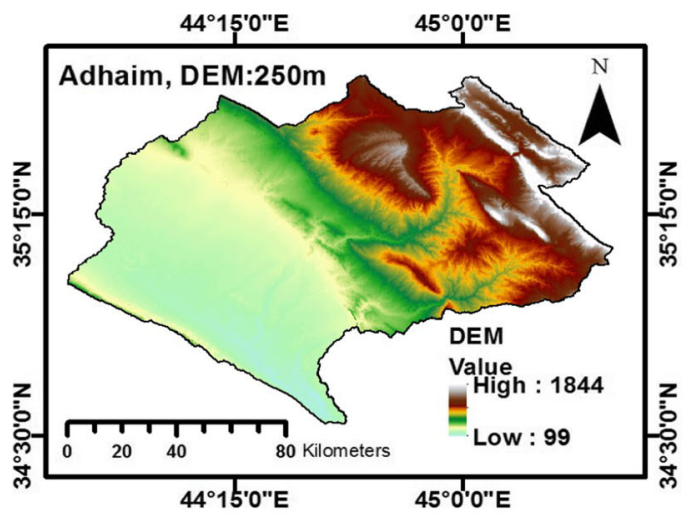

(b) $250 \mathrm{~m}$

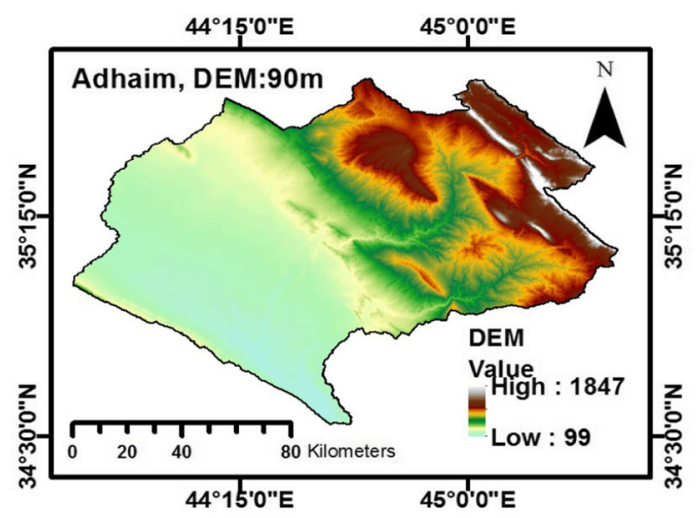

(c) $90 \mathrm{~m}$

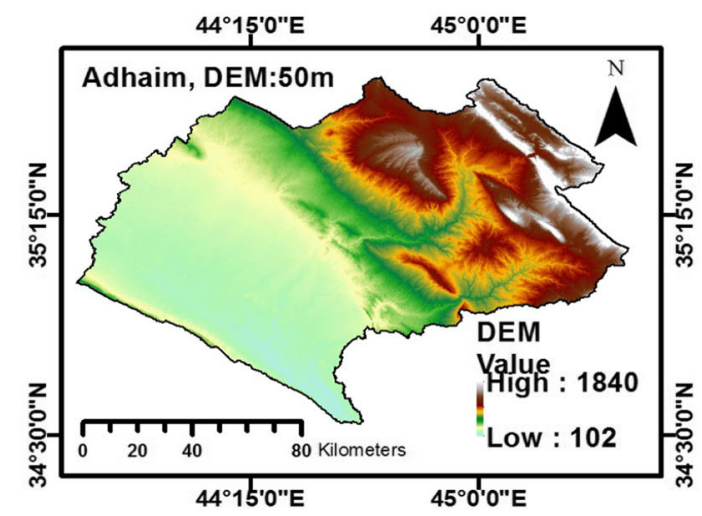

(d) $50 \mathrm{~m}$

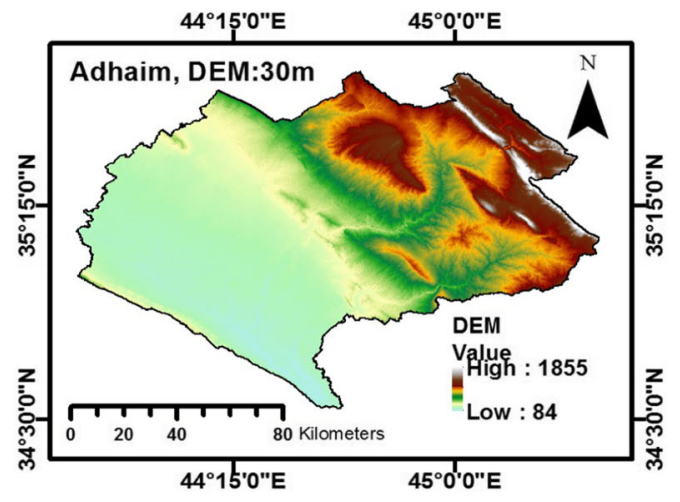

(e) $30 \mathrm{~m}$

Fig. 2 (continued)

slopes calculated by the SWAT. The LC was reclassified to match the SWAT database according to the similarity between LC classes and the SWAT database. To define and connect the LC and soil data to the SWAT, lookup tables were created in a compatible format. The HRUs were created with zero approximation for LC, slope and soil data to consider all classes of each of these items without approximation.

In this research, the SCS curve number $(\mathrm{CN})$, the Penman-Monteith formula and the variable storage method were used for rainfall-runoff modelling, to compute the ET and streamflow 
A

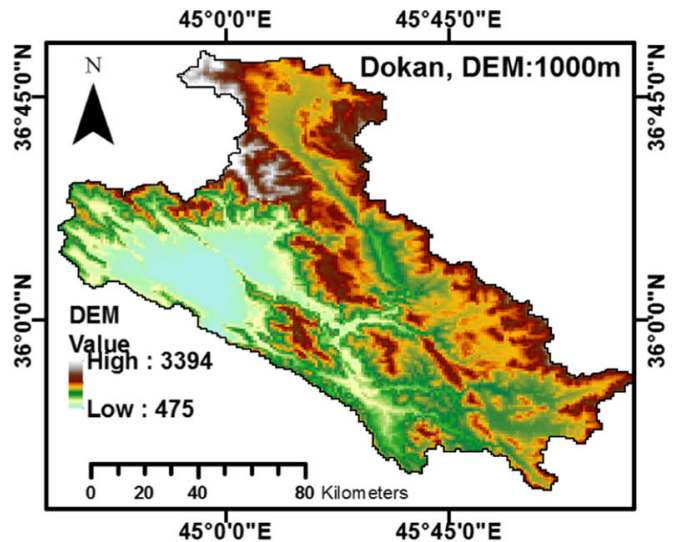

(a) $1000 \mathrm{~m}$

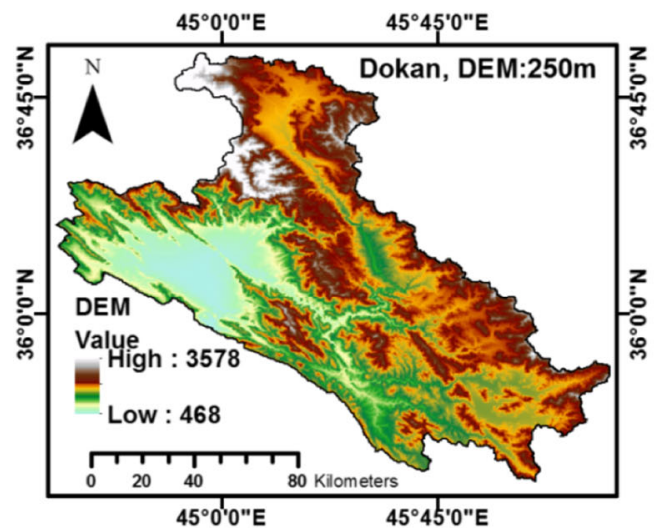

(b) $250 \mathrm{~m}$

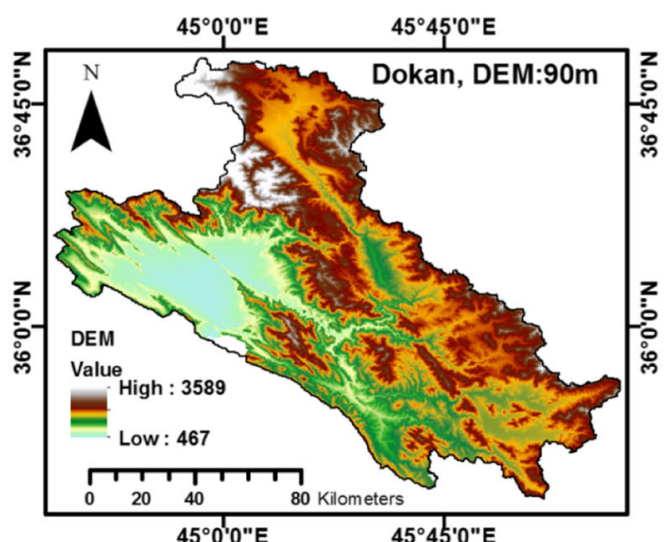

(c) $90 \mathrm{~m}$

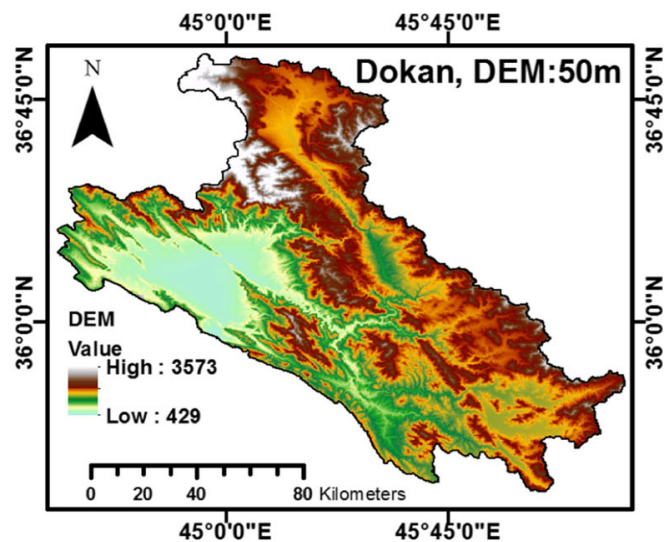

(d) $50 \mathrm{~m}$

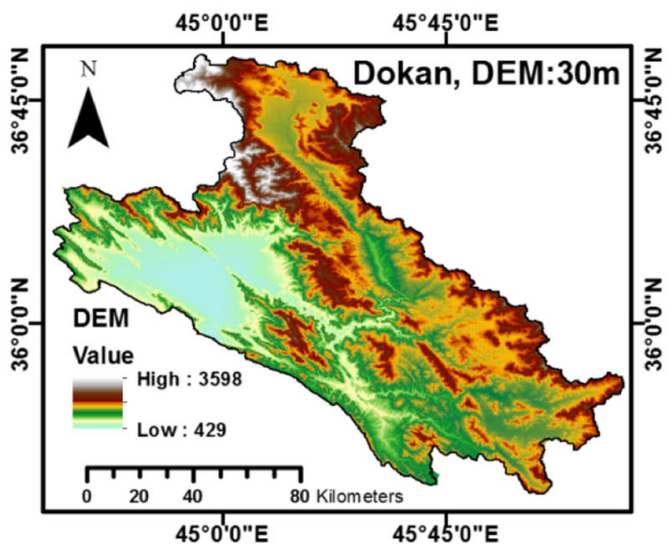

(e) $30 \mathrm{~m}$

Fig. 3 a DEMs of the DODW: (a) $1000 \mathrm{~m}$, (b) $250 \mathrm{~m}$, (c) $90 \mathrm{~m}$, (d) $50 \mathrm{~m}$ and (e) $30 \mathrm{~m}$. b LCs of the DUDW: (a) $1000 \mathrm{~m}$, (b) $500 \mathrm{~m}$, (c) $300 \mathrm{~m}$, (d) $30 \mathrm{~m}$ and (e) $15 \mathrm{~m}$

routing, respectively. The observed streamflow for 5 years, 2009 to 2013, was used to calibrate and validate the SWAT models of DUDW. While, observations over 4 years, 2010 to 2013, were used to calibrate and validate the SWAT models of ADDW and DODW models. 


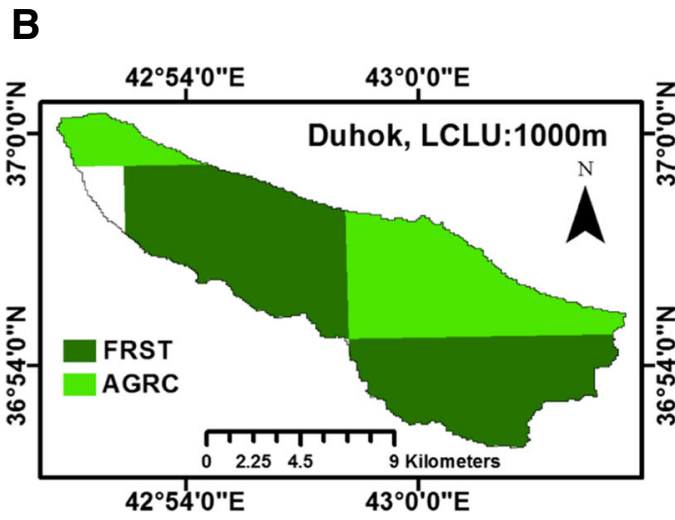

(a) $1000 \mathrm{~m}$

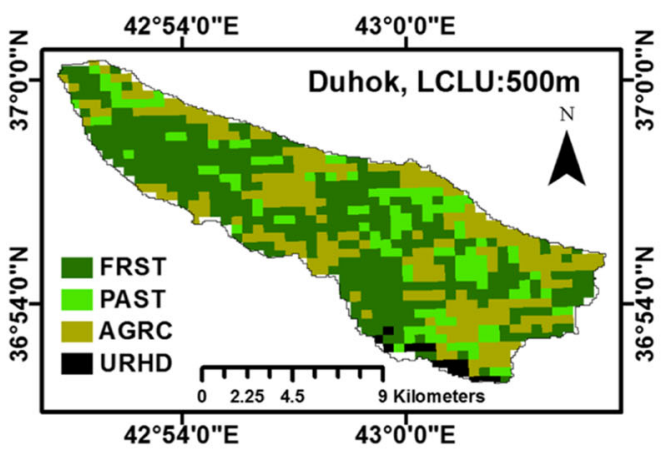

(b) $500 \mathrm{~m}$

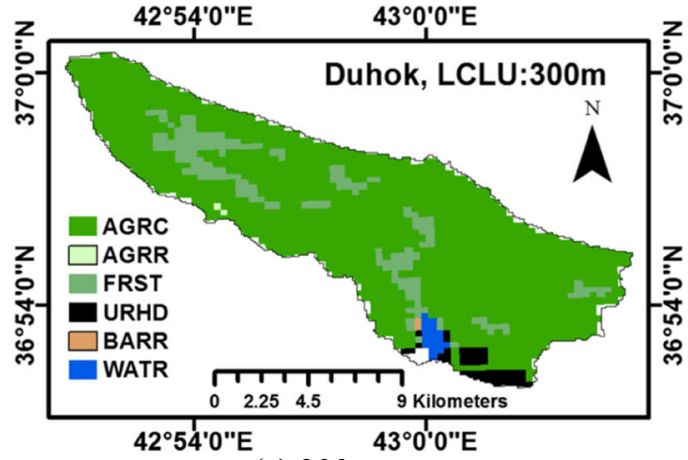

(c) $300 \mathrm{~m}$

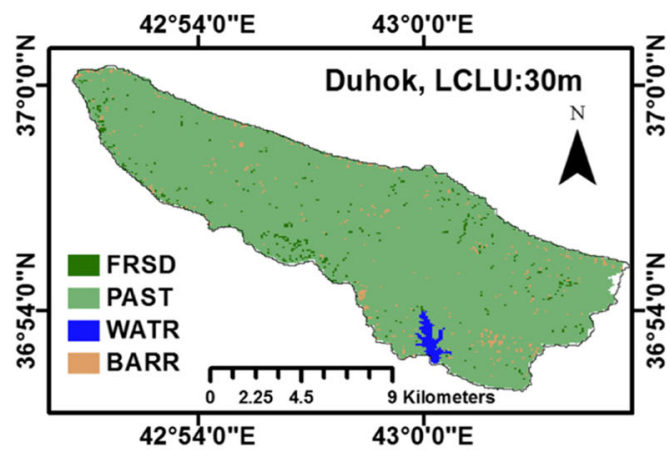

(d) $30 \mathrm{~m}$

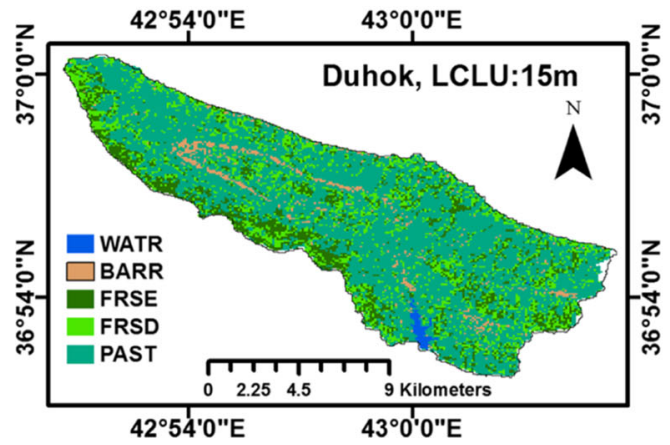

(e) $15 \mathrm{~m}$

Fig. 3 (continued)

\subsection{SWAT Model Calibration and Validation}

For the DUDW, ADDW and DODW models, the calibration and validation processes were performed using the SUFI-2 algorithm in the SWAT-CUP. The NS was set as the objective function in optimization and the $R^{2}$ as a minor indicator to evaluate the result of each scenario referring to input data of a different resolution. For the DUDW models, the data for 3 years, 2009 to 2011, were used for calibration, and data for the 2 years, 2012 to 2013, were used for validation. While, for both the ADDW and DODW models, the data for 2 years, 2010 to 2011, were used for calibration, and for the 2 years 2012 to 2013 were used for validation. Each model of different input data was calibrated independently (each model has independent calibration, validation and sensitivity analysis) using the sets of parameters suggested by Abbaspour et al. (2015) and other sets of parameters based on sensitivity analysis results. In the first iteration of the calibration process, using the SWAT-CUP, the 
A

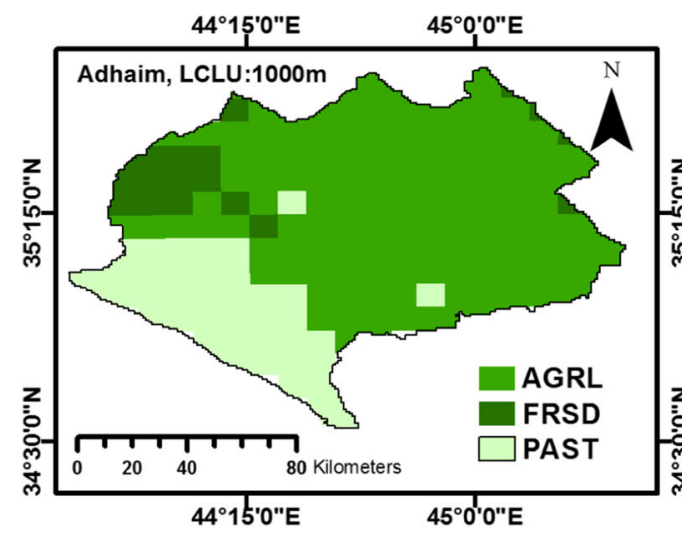

(a) $1000 \mathrm{~m}$

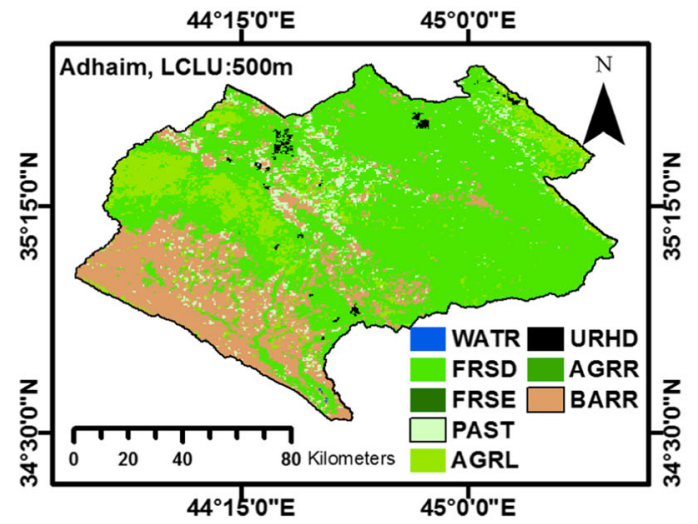

(b) $500 \mathrm{~m}$

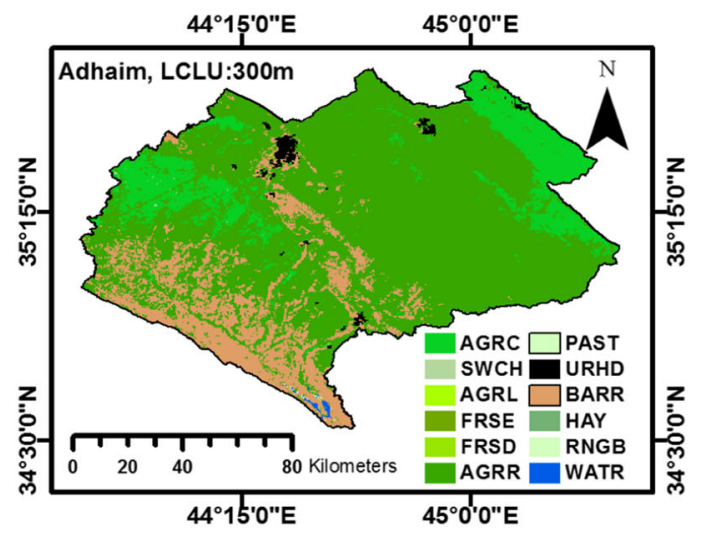

(c) $300 \mathrm{~m}$

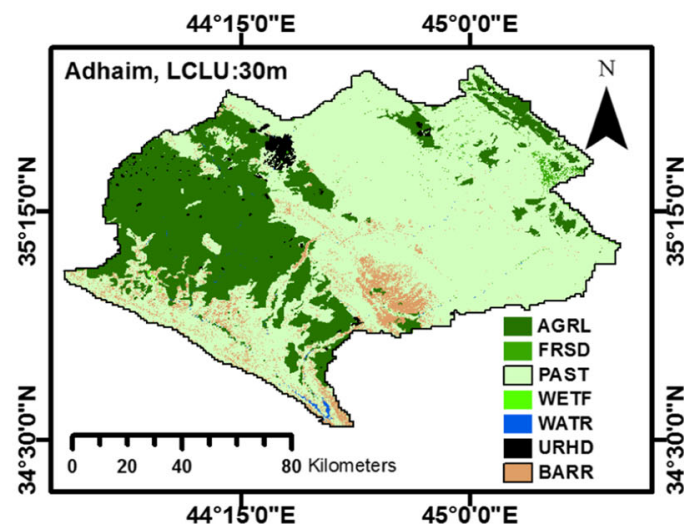

(d) $30 \mathrm{~m}$

Fig. 4. a LCs of the ADDW: (a) $1000 \mathrm{~m}$, (b) $500 \mathrm{~m}$, (c) $300 \mathrm{~m}$ and (d) $30 \mathrm{~m}$. b LCs of the DODW: (a) $1000 \mathrm{~m}$, (b) $500 \mathrm{~m}$, (c) $300 \mathrm{~m}$ and (d) $30 \mathrm{~m}$. c Soil map of the DUDW, ADDW and DODW

number of simulations was set up on a range of 200 to 300 simulations. However, for each model, the iteration number was set up on 2 to 5 iterations (Abbaspour et al. 2015). The validation processing was done by extracting the best ranges of calibrated parameters in the last iteration of calibration processing.

\section{Results and Discussions}

\subsection{Watershed Boundaries and Stream Networks}

Delineation of the DUDW, ADDW and DODW was obtained by applying the DEM-based method (DEMBM) in ArcSWAT (see Fig. 5a). For all the considered DEMs, delineation of the DUDW shows a very small difference in stream networks and watershed boundaries because a steep mountainous region surrounded this watershed (Fig. 5a). Whereas, the delineated boundaries and stream networks of the ADDW have a significant difference for the five DEMs considered (Fig. 5b). The difference is very clear in the western zone of this watershed because it has a flat topography. Whereas delineation of the DODW using the DEMs of 250, 90, 50 and $30 \mathrm{~m}$ produced the same boundaries and stream networks, the DEM of $1000 \mathrm{~m}$ shows significant differences in the boundaries and stream networks (see Fig. $5 \mathrm{c}$ ), because the DEMs of coarser resolution have less spatial distribution of altitudes. However, each DEM has its own spatial resolution with a specific magnitude of altitudes. The accuracy of these altitudes depends on the method of observation. In the SWAT, the DEM-BM depends on altitudes provided by the DEM to extract the required elevation in the calculation of watershed 


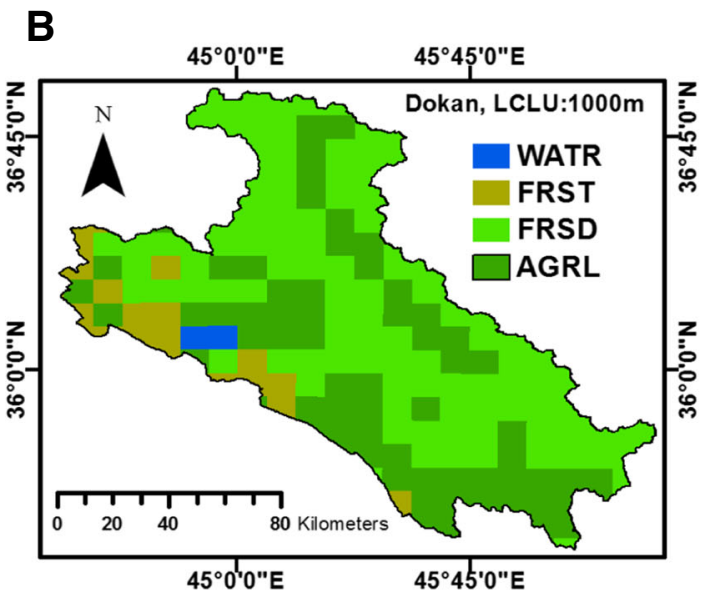

(a) $1000 \mathrm{~m}$

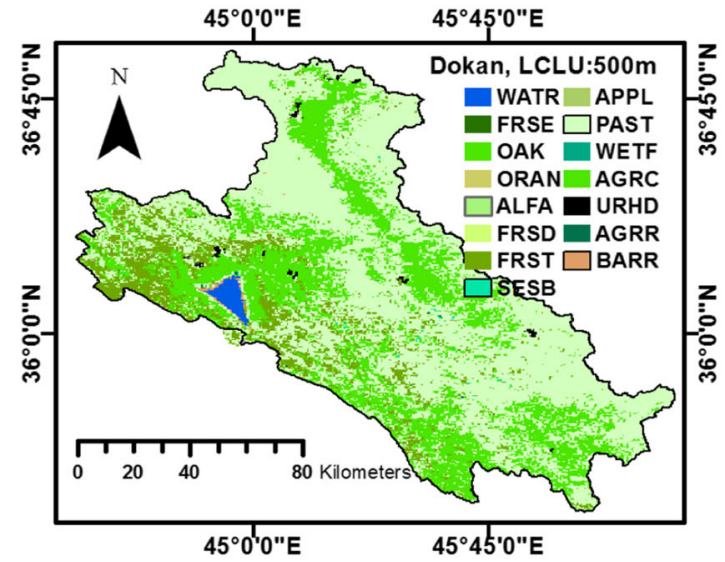

(b) $500 \mathrm{~m}$

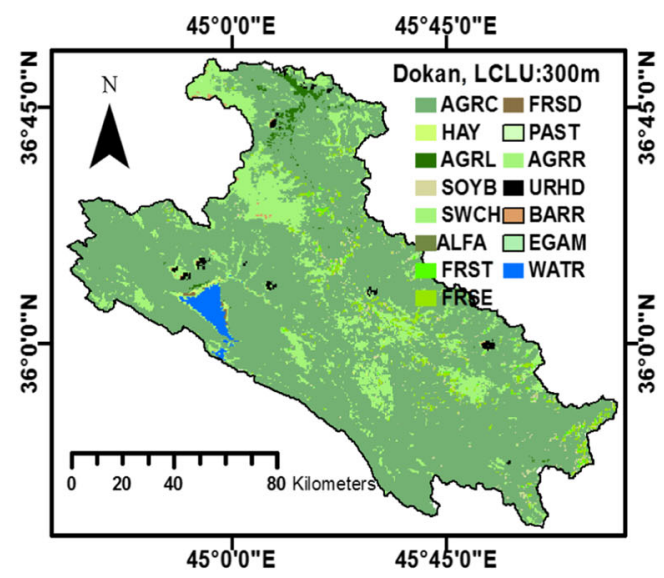

(c) $300 \mathrm{~m}$

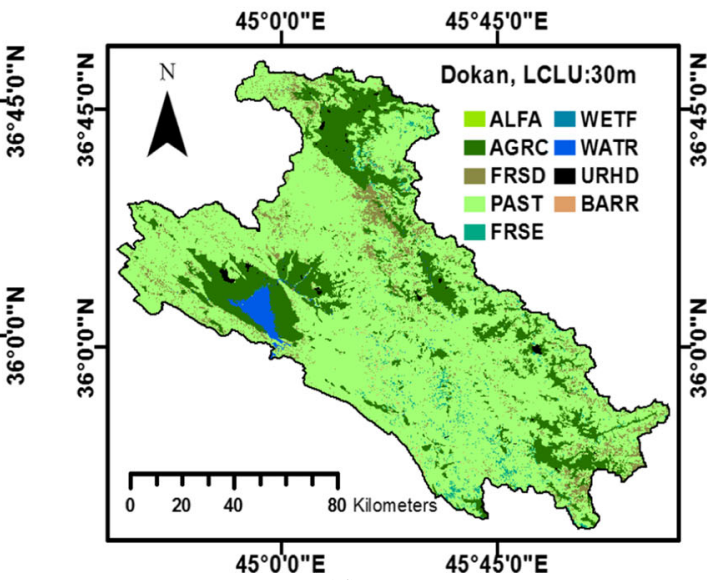

(d) $30 \mathrm{~m}$

Fig. 4 (continued)

boundaries and stream positions. In flat topography, there is little variance in altitude; this could be reflected in the ability of DEM-BM to obtain the required altitudes and to delineate the watershed.

\subsection{Watershed Area, Number of Subbasins and Altitudes}

Delineation of the considered watersheds using the DEM-BM shows that the DEM resolution has a significant impact on the computed watershed area, see Table 1. In the DUDW, which is the smallest watershed in this research, there is an inverse relationship between the computed watershed area and the DEM resolution. Whereas, in ADDW and DODW, which are larger than DUDW, no significant relationship is apparent between the computed watershed area and the DEM resolution. In addition, increasing the DEM resolution causes irregular change in the number of subbasins. The DEM resolution and the consequential maximum number of subbasins for the DUDW, ADDW and DODW were 7 subbasins with a DEM of 30, 50 and $90 \mathrm{~m}, 37$ subbasins with a DEM of $50 \mathrm{~m}$ and 35 subbasins with a DEM of $250 \mathrm{~m}$, respectively.

Figure $5 \mathrm{~b}$ shows that decreasing the DEM resolution (coarser DEM) caused an overprediction of the minimum elevations and under prediction of the maximum elevations. This is because using the DEM-BM increases the losses of topographic details with the decrease of the DEM resolution (coarser resolution). 


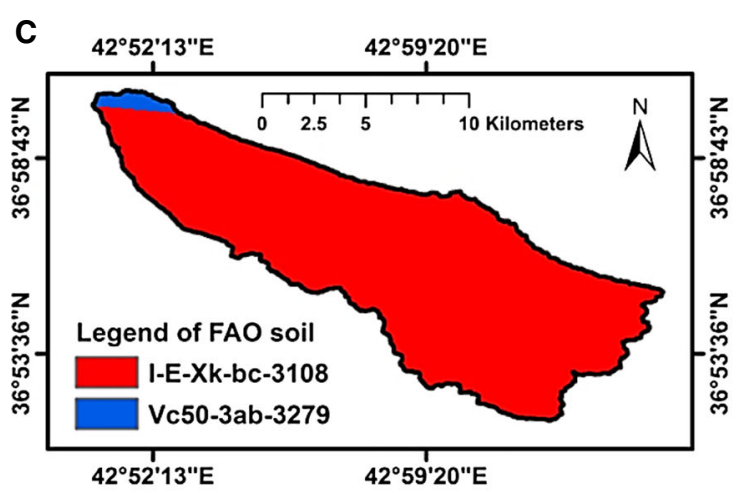

Soil map of the DUDW

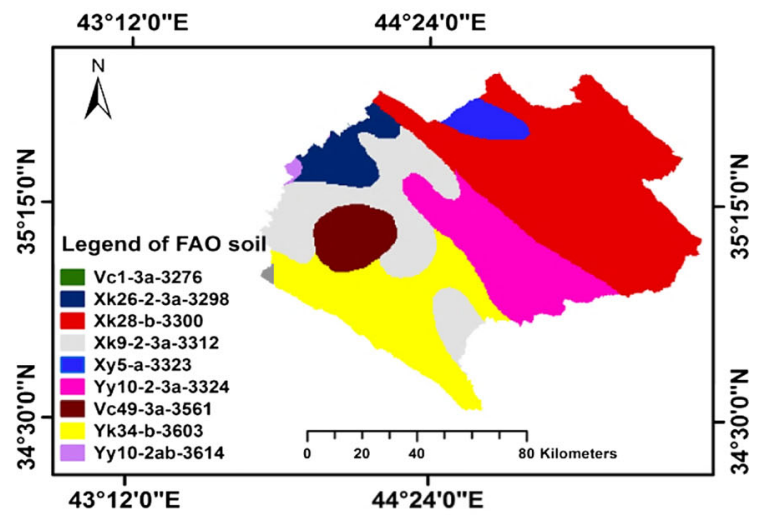

Soil map of the ADDW

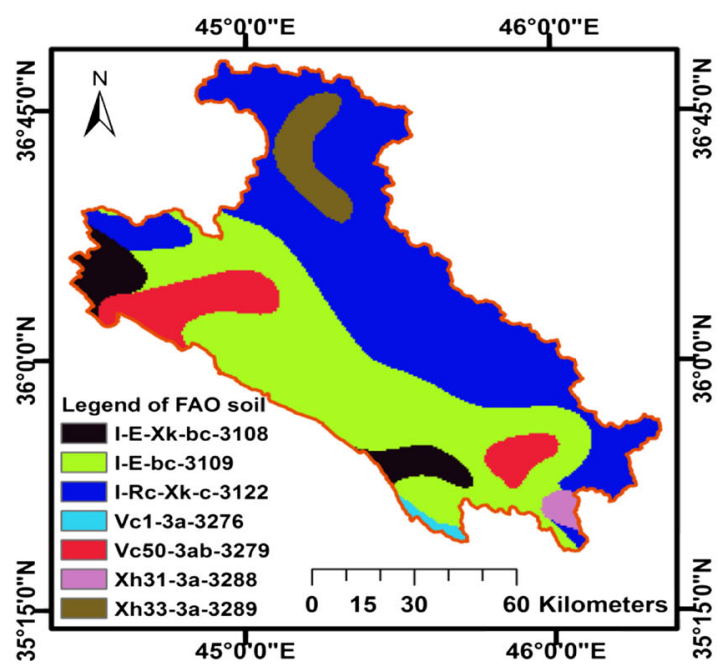

Soil map of the DODW

Fig. 4 (continued)

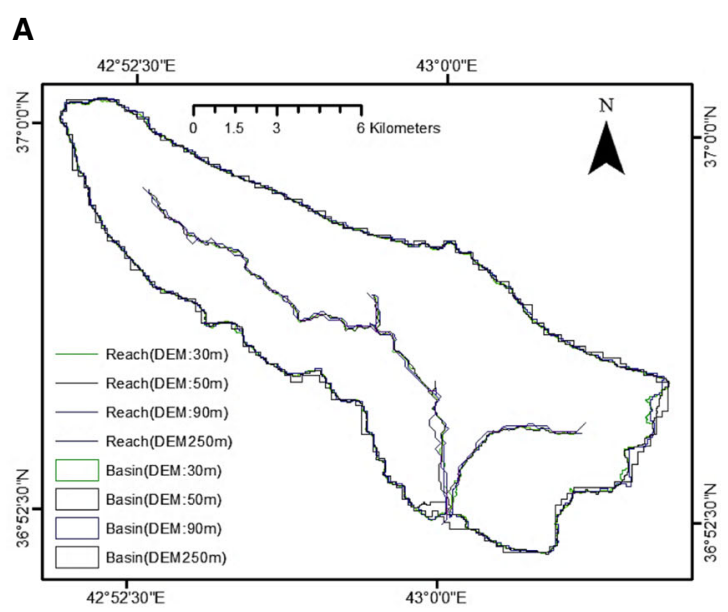

(a) DUDW

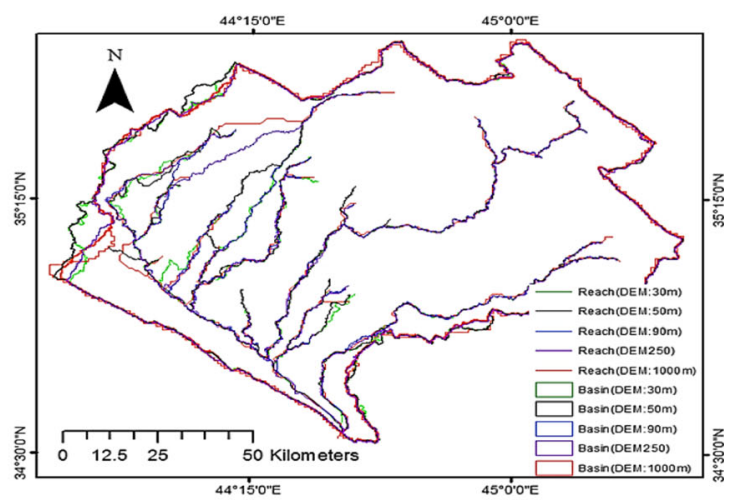

(b) ADDW

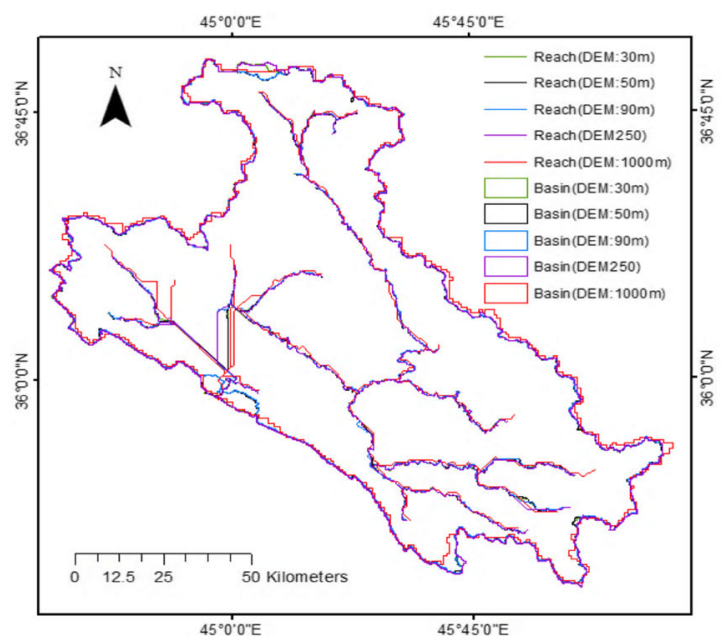

(c) DODW

Fig. 5 a Watershed delineation of (a) DUDW, (b) ADDW and (c) DODW. b DEM resolution versus minimum and maximum ground elevation: (a) DUDW, (b) ADDW and (c) DODW. c NHRUs versus LC and resolution: (a) DUDW, (b) ADDW and (c) DODW 


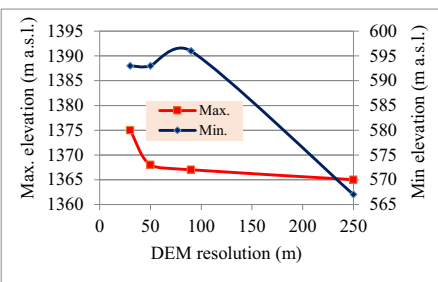

(a) DUDW

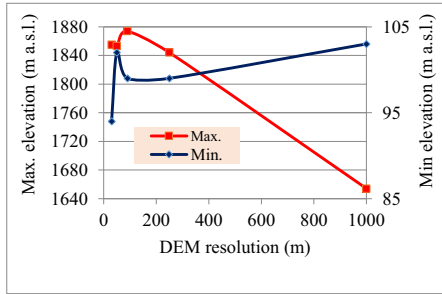

(b) ADDW

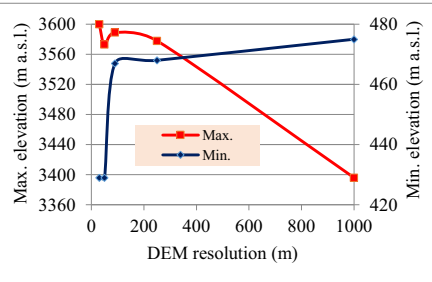

(c) DODW

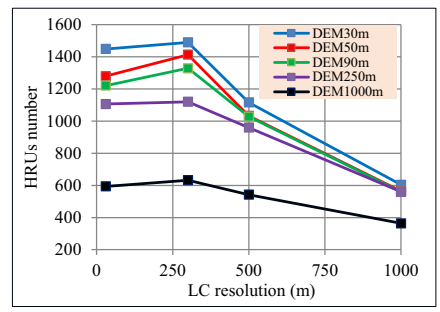

(a) DUDW

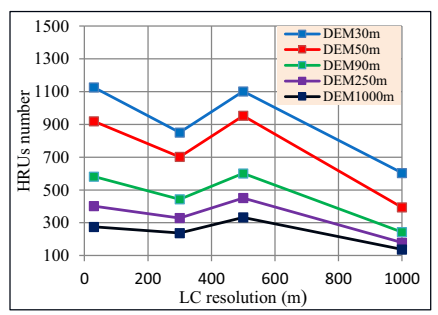

(b) ADDW

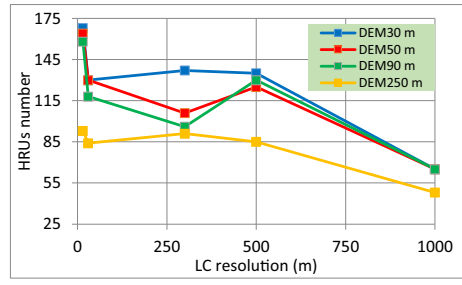

(c) DODW

Fig. 5 (continued)

\subsection{HRU Analysis}

For a particular LC, class number and LC resolution control the NHRUs, whereas for a particular DEM, only the slope controls the NHRUs. In this research, the interactive impact of LC and DEM resolution on the NHRUs created by the SWAT was evaluated (Fig. 5c). Comparison of the variation in the NHRUs with the LC for each DEM resolution shows that for each LC, the NHRUs decrease with the decrease in the DEM resolution, whereas the NHRUs increase with the decrease in $\mathrm{LC}$ resolution until a specific resolution of $\mathrm{LC}$ is reached thereafter the NHRUs decrease.

\subsection{Streamflow Evaluation}

For DUDW, the initial simulation (before calibration) of streamflow shows high base flow with high and late peaks of streamflow compared with the observed streamflow (simulated shift to right). While for ADDW and DODW, low base flow with high peaks and antecedent peaks of streamflow were computed (simulated shift to left) compared with the observed streamflow. Figure 6 shows the results of the best calibrated and validated SWAT models. For the DUDW, the best results of the validated SWAT model were obtained with the Landsat LC of $30-\mathrm{m}$ resolution and the ASTER DEM of $30-\mathrm{m}$ resolution with NS and $R^{2}$ of 0.69 and 0.69 , respectively. While the best results of the validated SWAT model of the ADDW were obtained with the MODIS LC of 1000-m resolution and the SRTM DEM of 250-m resolution with NS and $R^{2}$ of 0.68 and 0.74 , respectively. Moreover, for the DODW, the model with the MODIS LC of 1000-m resolution and the SRTM DEM of $90 \mathrm{~m}$ had the highest $\mathrm{NS}$ and $R^{2}$ values of 0.59 and 0.61 , respectively. According to Moriasi et al. (2007), the obtained values of NS and $R^{2}$ for all the selected best models are acceptable. The statistical indicators of this evaluation are listed in Tables 2, 3 and 4 . 
Table 1 Total area and number of subbasins of DUDW, ADDW and DODW

\begin{tabular}{|c|c|c|c|c|c|c|}
\hline \multirow[t]{2}{*}{ DEM resolution $(\mathrm{m})$} & \multicolumn{2}{|l|}{ Duhok } & \multicolumn{2}{|l|}{ Adhaim } & \multicolumn{2}{|l|}{ Dokan } \\
\hline & Area $\left(\mathrm{km}^{2}\right)$ & Subbasins & Area $\left(\mathrm{km}^{2}\right)$ & Subbasins & Area $\left(\mathrm{km}^{2}\right)$ & Subbasins \\
\hline 1000 & No model & & 11,979 & 33 & 11,552 & 31 \\
\hline 250 & 137.5 & 5 & 11,901 & 31 & 11,558 & 35 \\
\hline 90 & 135 & 7 & 11,910 & 35 & 11,336 & 33 \\
\hline 50 & 134.5 & 7 & 12,116 & 37 & 11,357 & 33 \\
\hline 30 & 133.8 & 7 & 12,013 & 33 & 11,499 & 33 \\
\hline
\end{tabular}

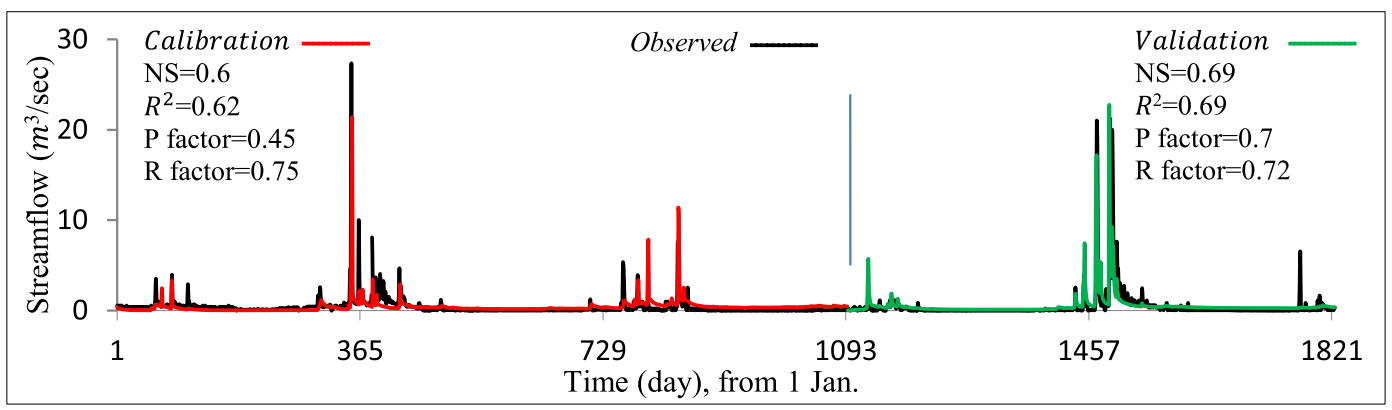

(a)

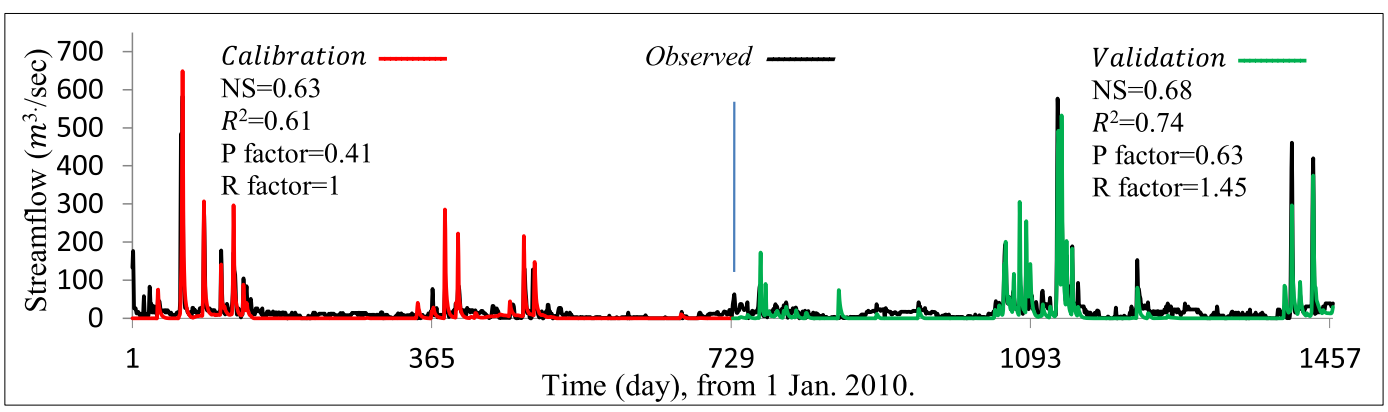

(b)

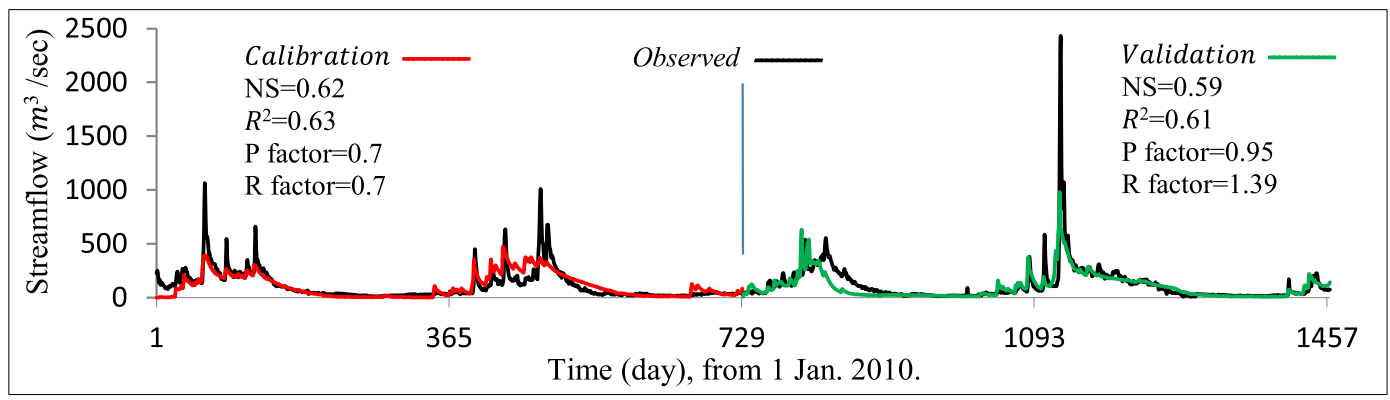

(c)

Fig. 6 Results of the best validated SWAT models of the considered watersheds: a DUDW (DEM 30 m, LC 30 m), b ADDW (DEM 250 m, LC $1000 \mathrm{~m}$ ) and c DODW (DEM $90 \mathrm{~m}, \mathrm{LC} 1000 \mathrm{~m}$ ) 
Table 2 Validation of the DUDW model

\begin{tabular}{llllll}
\hline DEM & LC & NSE & $R^{2}$ & P factor & R factor \\
\hline 30 & 15 & 0.6 & 0.64 & 0.69 & 0.95 \\
& 30 & 0.69 & 0.69 & 0.7 & 0.72 \\
& 300 & 0.63 & 0.66 & 0.5 & 0.66 \\
& 500 & 0.51 & 0.65 & 0.37 & 0.33 \\
50 & 1000 & 0.52 & 0.63 & 0.36 & 0.17 \\
& 15 & 0.57 & 0.58 & 0.14 & 0.23 \\
& 30 & 0.59 & 0.51 & 0.59 & 0.76 \\
& 300 & 0.61 & 0.63 & 0.56 & 0.61 \\
& 500 & 0.6 & 0.6 & 0.16 & 0.33 \\
& 1000 & 0.5 & 0.67 & 0.17 & 0.24 \\
& 15 & -0.13 & 0.42 & 0.23 & 0.2 \\
& 30 & 0.61 & 0.62 & 0.56 & 0.6 \\
& 300 & 0.61 & 0.62 & 0.56 & 0.6 \\
& 500 & 0.54 & 0.55 & 0.2 & 0.37 \\
& 1000 & 0.51 & 0.58 & 0.18 & 0.25 \\
& 15 & 0.58 & 0.59 & 0.54 & 0.64 \\
& 30 & 0.51 & 0.52 & 0.54 & 0.64 \\
& 300 & 0.52 & 0.58 & 0.48 & 0.7 \\
& 500 & 0.57 & 0.59 & 0.57 & 0.46 \\
& 1000 & 0.58 & 0.61 & 0.54 & 0.46 \\
\hline \multirow{5}{*}{50} & & & & &
\end{tabular}

Table 3 Validation of the ADDW model

\begin{tabular}{|c|c|c|c|c|c|}
\hline DEM & $\mathrm{LC}$ & NSE & $R^{2}$ & $\mathrm{P}$ factor & $\mathrm{R}$ factor \\
\hline \multirow[t]{4}{*}{30} & 30 & 0.61 & 0.66 & 0.68 & 1.61 \\
\hline & 300 & 0.66 & 0.66 & 0.46 & 0.62 \\
\hline & 500 & 0.56 & 0.68 & 0.53 & 1.22 \\
\hline & 1000 & 0.68 & 0.69 & 0.56 & 0.79 \\
\hline \multirow[t]{4}{*}{50} & 30 & 0.57 & 0.68 & 0.49 & 1.08 \\
\hline & 300 & 0.58 & 0.61 & 0.51 & 0.96 \\
\hline & 500 & 0.54 & 0.6 & 0.53 & 1.3 \\
\hline & 1000 & 0.68 & 0.69 & 0.67 & 1.7 \\
\hline \multirow[t]{4}{*}{90} & 30 & 0.66 & 0.69 & 0.57 & 0.8 \\
\hline & 300 & 0.6 & 0.62 & 0.63 & 1.38 \\
\hline & 500 & 0.59 & 0.63 & 0.4 & 0.57 \\
\hline & 1000 & 0.67 & 0.67 & 0.7 & 1.36 \\
\hline \multirow[t]{4}{*}{250} & 30 & 0.62 & 0.65 & 0.64 & 1.54 \\
\hline & 300 & 0.5 & 0.51 & 0.6 & 1.71 \\
\hline & 500 & 0.65 & 0.69 & 0.62 & 1.26 \\
\hline & 1000 & 0.68 & 0.74 & 0.63 & 1.45 \\
\hline \multirow[t]{4}{*}{1000} & 30 & 0.54 & 0.57 & 0.43 & 0.56 \\
\hline & 300 & 0.49 & 0.5 & 0.61 & 1.73 \\
\hline & 500 & 0.64 & 0.69 & 0.57 & 0.94 \\
\hline & 1000 & 0.63 & 0.69 & 0.65 & 1.4 \\
\hline
\end{tabular}

Table 4 Validation of the DODW model

\begin{tabular}{|c|c|c|c|c|c|}
\hline DEM & $\mathrm{LC}$ & NSE & $R^{2}$ & $\mathrm{P}$ factor & $\mathrm{R}$ factor \\
\hline \multirow[t]{4}{*}{30} & 30 & -0.15 & 0.53 & 0.55 & 1.34 \\
\hline & 300 & 0.34 & 0.45 & 0.77 & 0.96 \\
\hline & 500 & 0.5 & 0.94 & 0.94 & 2.63 \\
\hline & 1000 & 0.51 & 0.67 & 0.42 & 0.69 \\
\hline \multirow[t]{4}{*}{50} & 30 & 0.57 & 0.57 & 0.77 & 0.41 \\
\hline & 300 & 0.46 & 0.62 & 0.72 & 1.27 \\
\hline & 500 & -0.28 & 0.52 & 0.21 & 0.45 \\
\hline & 1000 & 0.18 & 0.54 & 0.54 & 0.66 \\
\hline \multirow[t]{4}{*}{90} & 30 & 0.35 & 0.66 & 0.66 & 1.1 \\
\hline & 300 & 0.48 & 0.59 & 0.69 & 0.7 \\
\hline & 500 & 0.47 & 0.52 & 0.85 & 0.92 \\
\hline & 1000 & 0.59 & 0.61 & 0.95 & 1.34 \\
\hline \multirow[t]{4}{*}{250} & 30 & 0.12 & 0.51 & 0.43 & 0.67 \\
\hline & 300 & 0.24 & 0.31 & 0.98 & 1.38 \\
\hline & 500 & 0.46 & 0.59 & 0.95 & 2.57 \\
\hline & 1000 & 0.19 & 0.38 & 0.82 & 1.03 \\
\hline \multirow[t]{4}{*}{1000} & 30 & 0.03 & 0.47 & 0.34 & 0.69 \\
\hline & 300 & 0.23 & 0.37 & 0.87 & 1.27 \\
\hline & 500 & -0.43 & 0.49 & 0.7 & 1.5 \\
\hline & 1000 & 0.53 & 0.59 & 0.32 & 0.7 \\
\hline
\end{tabular}

\section{Conclusions}

In this paper, the sensitivity of the SWAT model to the resolution of LC and DEM data for watersheds of different LC, size and topography characteristics was examined. Three watersheds located in Iraq, DUDW, ADDW and DODW formed the study area. Analysis of the results of the implemented SWAT models for the considered watersheds illustrates that the obtained watershed boundary, stream network configuration and total watershed area through the delineation process are closely related to the DEM resolution and watershed terrain characteristics, especially with regard to the watersheds with flat topography. However, decreasing the accuracy or detail of topographic data with the decreased (coarser) DEM resolution produces an underestimate and overestimate for the maximum and minimum elevations, respectively. Moreover, the number of subbasins changed unevenly with the decrease in the DEM resolution.

The results indicate that for each DEM resolution, there is no significant trend or relationship between the NHRUs and LC resolution. While for each LC resolution, the NHRU decreases with the decrease in the DEM 
resolution. Although the area of DODW is smaller than the ADDW for all resulting models, DODW has more NHRUs than ADDW because the variance in LC and slopes in the ADDW is lower than those of the DODW. In other words, the LC, slope and soil characteristics control the NHRUs. Consequently, the smaller variances in these elements create less NHRUs and vice versa. Accordingly, the fine resolution of input data used in the SWAT generates large NHRUs, which require more storage space and longer runtimes, calibration and validation; moreover, using finer resolutions of DEM and LC in the SWAT does not necessarily provide an accurate simulation of streamflow even with calibration. This is because the large NHRUs generate more hydrologic parameters that are calibrated against just one observed variable, which is the observed streamflow. In addition, there are some differences between LC classes nominated by producers and LC classes in the SWAT database, so defining these classes to a matching SWAT database contains more uncertainty especially for models of large NHRUs (models of finer resolution input data). To obtain accurate streamflow prediction for DUDW, ADDW and DODW by using the SWAT model, it is advisable to use the Landsat LC of 30-m resolution for DUDW and the MODIS LC of $1000 \mathrm{~m}$ for ADDW and DODW and the ASTER DEM of $30 \mathrm{~m}$, SRTM DEM of $250 \mathrm{~m}$ and SRTM DEM of 90-m resolution for the DUDW, ADDW and DODW, respectively. However, the recommended input data for the considered watersheds does not necessarily give the same results with other watersheds. The input data of this study could not be generalized to other watersheds, and each watershed should implement on different resolutions and sources of input data in order to obtain the simulation which best represents the real characteristics of a watershed. Due to unavailability of wide range of spatial resolution for both DEM and LC in each source of input data to be examined, the variability in the resolution which achieved best simulation can be overall addressed to the spatial resolution and the type of input data as well as method of input data acquired. The sensitivity of other hydrological or environmental processing such as sediment or pollution simulated by the SWAT based on the resolution of input data requires more investigation. Furthermore, it is recommended that more sources and resolutions of soil data are used to investigate the interactive impact of spatial input data (DEM, LC and soil) on the results of the SWAT models.
Acknowledgements Thanks and sincere gratitude to the technical and faculty staff of the Department of Civil Engineering at the University of Technology, Baghdad, for their valuable support and scientific assistance. Also, gratitude and thankfulness to the Ministry of Water Resources, Iraq, for their assistance in conducting the field investigations and providing the data.

Funding Information Open access funding provided by Lulea University of Technology.

Open Access This article is licensed under a Creative Commons Attribution 4.0 International License, which permits use, sharing, adaptation, distribution and reproduction in any medium or format, as long as you give appropriate credit to the original author(s) and the source, provide a link to the Creative Commons licence, and indicate if changes were made. The images or other third party material in this article are included in the article's Creative Commons licence, unless indicated otherwise in a credit line to the material. If material is not included in the article's Creative Commons licence and your intended use is not permitted by statutory regulation or exceeds the permitted use, you will need to obtain permission directly from the copyright holder. To view a copy of this licence, visit http://creativecommons.org/licenses/by/4.0/.

\section{References}

Abbaspour, K. C., Rouholahnejad, E., Vaghefi, S., Srinivasan, R., Yang, H., \& Kløve, B. (2015). A continental-scale hydrology and water quality model for Europe: calibration and uncertainty of a high-resolution large-scale SWAT model. Journal of Hydrology, 524, 733-752. https://doi.org/10.1016/j. jhydrol.2015.03.027.

Al_Amawy, F. H., \& Wahib, N. R. (2015). Determinants of climate controls for climate of Diyala province. Journal of Research Diyala Humanity, 67, 419-433 https://www.iasj. net/iasj?func=article \&aId $=107717$.

Arnold, J. G., Srinivasan, R., Muttiah, R. S., \& Williams, J. R. (1998). Large area hydrologic modeling and assessmentpart 1: model development. Journal of the American Water Resources Association, 34, 73-89. https://doi.org/10.1111 j.1752-1688.1998.tb05961.x.

Arnold, J. G., Gassman, P. W., Abbaspour, K. C., White, M. J., Srinivasan, R., Santhi, C., Harmel, R. D., Van Griensven, A., Van Liew, M. W., Kannan, N., \& Jha, M. K. (2012). SWAT model use, calibration and validation. Transactions of the $A S A B E$, 55(4), 1491-1508. https://doi.org/10.13031 $/ 2013.42256$.

Booij, M. J. (2005). Impact of climate change on river flooding assessed with different spatial model resolutions. Journal of Hydrology, 303, 176-198.

Casper, A. F., Dixon, B., Earls, J., \& Gore, J. A. (2011). Linking a spatially explicit watershed model (SWAT) with an in-stream fish habitat model (PHABSIM): a case study of setting minimum flows and levels in a low gradient, sub-tropical river. River Research and Applications, 27, 269-282. https://doi. org/10.1002/rra.1355.

CFSR (Climate Forecast System Reanalysis) dataset (2015) [Online]. Available: http://globalweather.tamu.edu. 
Chaplot, V. (2005). Impact of DEM mesh size and soil map scale on SWAT runoff, sediment, and NO3-N loads predictions. Journal of Hydrology, 312, 207-222. https://doi.org/10.1016 /j.jhydrol.2005.02.017.

Chaubey, I., Cotter, A. S., Costello, T. A., \& Soerens, T. S. (2005). Effect of DEM data resolution on SWAT output uncertainty. Hydrological Processes, 19, 621-628. https://doi. org/10.1002/hyp.5607.

Chen, L., 2014. 30-meter global land cover dataset (globalland30), 2014. [online]. Available: http://www.globallandcover. com/GLC30Download/index.aspx.

Chen, P. Y., Luzio, M. Di., Arnold, J. G. 2005. Impact of two land cover sets on stream flow and total nitrogen simulations using a spatially distributed hydrologic mode. Pecora 16: Global Priorities in Land Remote Sensing, Sioux Falls, South Dakota, October 23-27.

Dixon, B. (2009). Resample or not?! Effects of resolution of DEMs in watershed modelling. Hydrological Processes, 23, 1714-1724. https://doi.org/10.1002/hyp.7306.

FAO (Food and Agricultural Organization). (2003). Digital soil map of the world and derived soil properties [CD-ROM], Version 3.5. Rome.

Frenken, K., 2009. Irrigation in the Middle East region in figures, AQUASTAT survey 2008, water reps., Rome: FAO, ISBN 978-92-5-106316-3, 34, 199-213.

Fuka, D. R., Walter, M. T., MacAlister, C., Degaetano, A. T., Steenhuis, T. S., \& Easton, Z. M. (2013). Using the climate forecast system reanalysis as weather input data for watershed models. Hydrological Processes, published on line library, available. https://doi.org/10.1002/hyp.10073.

Gassman, P. W., Reyes, M. R., Green, \& Arnold, C. H. (2007). The soil and water assessment tool: historical development, applications and future research directions. American Society of Agricultural and Biological Engineers, ISSN 0001-2351, 50(4), 1211-1250.

GTOPO30: Global digital elevation model, [Online], 2015. Available: http://earthexplorer.usgs.gov/

Hargreaves, G. H., \& Samani, Z. A. (1985). Reference crop evapotranspiration from temperature. Applied Engineering in Agriculture, 1, 96-99.

Jarihani, A. A., Callow, N., Mcvicar, T. R., Van Niel, T. G., \& Larsen, J. R. (2015). Satellite-derived digital elevation model (DEM) selection, preparation and correction for hydrodynamic modelling in large, low-gradient and data-sparse catchments. Journal of Hydrology, 524, 489-506. https://doi.org/10.1016/j.jhydrol.2015.02.049.

Katrin, B., Georg, H. R., \& Nicola, F. (2011). Simulation of stream flow and sediment with the soil and water assessment tool in a data scarce catchment in the three Gorges Region, China. Journal of Environmental Quality, 37-45. https://doi. org/10.2134/jeq2011.0383.

Li, W., Ciais, P., MacBean, N., Peng, S., Defourny, P., \& Bontemps, S. (2016). Major forest changes and land cover transitions based on plant. International Journal of Applied Earth Observation and Geoinformation, 47, 30-39. https://doi.org/10.1016/j.jag.2015.12.006.

Lin, S., Jing, C., Coles, N. A., Chaplot, V., Moore, N. J., \& Wu, J. (2013). Evaluating DEM source and resolution uncertainties in the soil and water assessment tool. Stochastic Environmental Research and Risk Assessment, 27(1), 209 221. https://doi.org/10.1007/s00477-012-0577-x.

Meins, F. M. (2013). Evaluation of spatial scale alternatives for hydrological modelling of the Lake Naivasha basin, Kenya, Thesis (M.Sc.). Enschede: University of Twente.

Mohammed, R. H. (2010). The impact of the man activity in Duhok Dam watershed on the future of Duhok Dam lake North-Iraq, 1st Int. Appl. Geolog. Congr., Dept. of Geol., Islamic Azad University-Mashad Branch, Iran, 783-788, April 26-28.

Monteith, J. L. (1965). Evaporation and the environment. InIn the state and movement of water in living organisms. $19^{\text {th }}$ Symposia of the Society for Experimental Biology (pp. 205234). London, U.K.: Cambridge University Press.

Moriasi, D. N., Arnold, J. G., Van Liew, M. W., Bingner, R. L., Harmel, R. D., \& Veith, T. L. (2007). Model evaluation guidelines for systematic quantification of accuracy in watershed simulations. Transactions of the ASABE, 50(3), 885900. https://doi.org/10.13031/2013.23153.

Muchoney, D., Strahler, A., Hodges, J., \& Castro, J. L. (1999). The IGBP DIS cover confidence site and the system for terrestrial ecosystem parameterization: tools for validating global land cover data. Photogrammetric Engineering and Remote Sensing, 65(9), 1061-1067.

Nash, J. E., \& Sutcliffe, J. V. (1970). River flow forecasting through conceptual models part 1: a discussion of principles. Journal of Hydrology, 10(3), 282-290. https://doi. org/10.1016/0022-1694(70)90255-6.

Neitsch, S. L., Arnold, J. G., Kiniry, J. R., and Grassland, J. R. W., 2011. Soil and water assessment tool theoretical documentation version 2009, Texas A\&M University, College Station, TX, USA, Texas Water Resour. Inst. Tech. Rep. No. 406. http://hdl.handle.net/1969.1/128050.

Priestly, C. H. B., \& Tylor, R. J. (1972). On the assessment of surface heat flux and evaporation using large-scale parameters. Monthly Weather Review, 100, 81-92. https://doi. org/10.1175/1520-0493(1972)100<0081:OTAOSH $>2.3$. $\mathrm{CO} ; 2$.

Rao, M. N., \& Yang, Z. (2010). Groundwater impacts due to conservation reserve program in Texas County, Oklahoma. Applied Geography, 30(3), 317-328. https://doi.org/10.1016 /j.apgeog.2009.08.006.

Reddy, S., \& Reddy, M. J. (2015). Evaluating the influence of spatial resolutions of DEM on watershed runoff and sediment yield using SWAT. Journal of Earth System Science, 124(7), 1517-1529.

Romanowicza, A. A., Vanclooster, M. M., Rounsevell, \& La Junesse, I. (2005). Sensitivity of the SWAT model to the soil and land use data parametrisation: a case study in the Thyle catchment, Belgium. Ecological Modelling, 187, 27-39. https://doi.org/10.1016/j.ecolmodel.2005.01.025.

Sloan, P. G. (1984). Modeling subsurface stormflow on steeply sloping forested watersheds. Water Resources Research, 20(12), 1815-1822. https://doi.org/10.1029/WR020i012 p01815.

Soil Conservation Service Engineering Division. (1986). Urban hydrology for small watershed. U.S. Department of 
Agriculture, Technical Release 55. SRTM. (2015). Global digital elevation model. http://glcf.umd.edu /data/srtm/.

SRTM, 2015. Global digital elevation model. http://glcf.umd.edu /data/srtm/.

Tan, M. L., Ficklin, D. L., Dixon, B., Ibrahim, A. L., Yusop, Z., \& Chaplot, V. (2015). Impacts of DEM resolution, source, and resampling technique on SWAT-simulated stream flow. Applied Geography, 63, 357-368. https://doi.org/10.1016/j. apgeog.2015.07.014.

Tomy, T., \& Sumam, K. S. (2016). Determining the adequacy of CFSR data for rainfall-runoff modeling using SWAT. Procedia Technology, 24, 309-316. https://doi.org/10.1016 j.protcy.2016.05.041.
Wolockm, D. M., \& Price, C. V. (1994). Effects of digital elevation model map scale and data resolution on a topographybased watershed model. Water Resources Research, 30(11), 3041-3052. https://doi.org/10.1029/94WR01971.

Zhang, P., Liu, R., Bao, Y., Wang, J., Yu, W., \& Shen, Z. (2014). Uncertainty of SWAT model at different DEM resolutions in a large mountainous watershed. Water Research, 53, 132144. https://doi.org/10.1016/j.watres.2014.01.018.

Publisher's Note Springer Nature remains neutral with regard to jurisdictional claims in published maps and institutional affiliations. 